\title{
ON SOME COUPLED SYSTEMS OF FRACTIONAL DIFFERENTIAL INCLUSIONS
}

\section{AURELIAN CERNEA}

Abstract. We study certain coupled systems of fractional differential inclusions with several boundary conditions and we obtain the existence of solutions in the situation when the set-valued maps have non-convex values.

Mathematics subject classification (2020): 34A60, 26A33, 34B15.

Keywords and phrases: Fractional derivative, differential inclusion, boundary conditions.

\section{REFERENCES}

[1] S. Abbas, M. Benchohra And Y. Zhou, Coupled Hilfer fractional differential systems with random effects, Adv. Difference Equ. 2018, no. 369, (2018), 1-12.

[2] S. Abbas, N. A. Arifi, M. Benchohra And J. Henderson, Coupled Hilfer and Hadamard random fractional differential systems with finite delay in generalized Banach spaces, Differ. Equ. Appl. 12, (2020), 337-353.

[3] B. Ahmad, A. Alsaedi And S. K. Ntouyas, Nonlinear coupled fractional order systems with integro-multistrip-multipoint boundary conditions, Int. J. Anal. Appl. 17, (2019), 940-957.

[4] B. Ahmad, S. K. NTOuYAs AND A. Als AEDi, Coupled systems of fractional differential inclusions with coupled boundary conditions, Electron. J. Diff. Equ. 2019, (2019), no. 69, 1-21.

[5] J. P. Aubin And H. Frankows Ka, Set-valued Analysis, Birkhauser, Basel, 1990.

[6] D. Băleanu, K. Diethelm, E. Scalas and J. J. Trujillo, Fractional Calculus Models and Numerical Methods, World Scientific, Singapore, 2012.

[7] A. CERnEA, On some fractional differential inclusions with random parameters, Frac. Calc. Appl. Anal. 21, (2018), 190-199.

[8] A. CERnEA, Existence of solutions for some coupled systems of fractional differential inclusions, MDPI Mathematics 8, no. 700, (2020), 1-10.

[9] K. Diethelm, The Analysis of Fractional Differential Equations, Springer, Berlin, 2010.

[10] A. F. FILIPPOV, Classical solutions of differential equations with multivalued right hand side, SIAM J. Control, 5, (1967) 609-621.

[11] J. Hadamard, Essai sur l'etude des fonctions donnees par leur development de Taylor, J. Math. Pures Appl. 8, (1892), 101-186.

[12] R. HiLfER, Applications of Fractional Calculus in Physics, World Scientific, Singapore, 2010.

[13] A. A. Kilbas, Hadamard-type fractional calculus, J. Korean Math. Soc. 38, (2001), 1191-1204.

[14] A. A. Kilbas, H. M. SRivastava And J. J. Trujillo, Theory and Applications of Fractional Differential Equations, Elsevier, Amsterdam, 2006.

[15] K. Miller AND B. Ross, An Introduction to the Fractional Calculus and Differential Equations, John Wiley, New York, USA, 1993.

[16] S. K. NTOUYAS AND H. H. AL-Sulami, A study of coupled systems of mixed order fractional differential equations and inclusions with coupled integral fractional boundary conditions, Adv. Difference Equ. 2020, no. 73, (2020), 1-21.

[17] I. Podlubny, Fractional Differential Equations, Academic Press, San Diego, USA, 1999.

[18] S. N. RAO AND M. AlSEMI, On a coupled system of fractional differential equations with nonlocal non-separeted boundary conditions, Adv. Difference Equ. 2019, no. 97, (2019), 1-17. 